\title{
Prolonged Intestinal Absorption of Cephradine with Chitosan-Coated Ethylcellulose Microparticles in Rats
}

\author{
Junko TaKishima, Hiraku ONISHI,* and Yoshiharu Machida \\ Department of Drug Delivery Research, Hoshi University; 2-4-41 Ebara, Shinagawa-ku, Tokyo 142-8501, Japan. \\ Received May 2, 2002; accepted August 20, 2002
}

\begin{abstract}
Cephradine-containing ethylcellulose microparticles (MPC) were prepared by the solvent evaporation method. Chitosan-coated MPC (Chi-MPC) were prepared by doping MPC with viscous chitosan solution and subsequently drying. When fluorescein isothiocyanate (FITC)-labeled chitosan-coated ethylcellulose microparticles without drug were administered intraduodenally, they moved slowly in the intestine, that is, most of them were retained at the upper and middle parts of the small intestine for more than $8 \mathrm{~h}$, which is considered due to mucoadhesive properties of coated chitosan. When MPC and Chi-MPC was incubated at $37^{\circ} \mathrm{C}$ in the JP 14 second fluid, $\mathrm{pH} 6.8$, both released the drug slowly with similar release rates. Cephradine solution and suspension, MPC and Chi-MPC were administered intraduodenally to investigate intestinal drug absorption. Only Chi-MPC suppressed the initial plasma level and maintained the plasma concentration for a long time up to $24 \mathrm{~h}$, suggesting Chi-MPC would be useful for prolonged intestinal absorption of cephradine.
\end{abstract}

Key words chitosan-coated ethylcellulose microparticle; cephradine; intestinal absorption; mucoadhesive property; intraduodenal administration

Following oral administration, drug absorption behavior can be affected by drug release, gastrointestinal transit rate etc. The modification of drug release has been extensively investigated by pharmaceutical processing using various additives. ${ }^{1-3)}$ Gastric floating system is known as one approach to modify gastrointestinal transit rate. ${ }^{4,5)}$ This system may enhance absorption from the stomach and subsequently from intestine, but such system is not available for drugs that are unstable at acidic $\mathrm{pH}$. As tablet dosage forms have a large mass, it is considered difficult to control their intestinal transit rate. On the other hand, microparticulate dosage forms are useful for control of intestinal transit due to their small mass. Microparticulate dosage forms are often used for controlled drug release. ${ }^{1,6-8)}$ Further, their gastrointestinal transit can be modified with mucoadhesive polymers. ${ }^{9-11)}$ When the mucoadhesive polymers interact with mucous membranes of the GI tract, they are considered to be localized or trapped at the adhesive sites, which may result in prolonged duration of absorption. ${ }^{7,12-14)}$ Chitosan is adhesive to the intestinal mucosa, and chitosan enhances drug absorption from microparticulate dosage forms. ${ }^{7,10,11)}$ The mucoadhesive properties and transit of chitosan microparticles in the rat small intestine were reported previously. ${ }^{14)}$ Chitosan enhanced the localization and retention at the small intestine in the microparticulate dosage form. This property was considered useful for prolongation of intestinal absorption. Especially, when sustained release microparticles of drugs with a short biological half life are localized at good absorption sites, sustained action can be achieved, resulting in less frequent dosing. Thus, in the present study, cephradine, an amino- $\beta$-lactam antibiotic agent with a short half life, ${ }^{15-21)}$ was chosen as a model drug, and chitosan-coated prolonged release microparticles were prepared and evaluated with regard to intestinal transit and drug absorption.

\section{MATERIALS AND METHODS}

Chemicals Cephradine and fluorescein isothiocyanate (FITC) were purchased from Sigma Chemical Co. (St. Louis,
MO, U.S.A.). Chitosan (Daichitosan H) with a deacetylation degree of $82 \%$ (sugar unit mol) and molecular weight of 500000 - 800000, named Chi, was supplied by Dainichi Seika Color and Chemicals Mfg. Co., Ltd. (Tokyo, Japan). Sorbitan tristearate (SS-30) was obtained from Nikko Chemicals (Tokyo, Japan). Ethyl cellulose (49\% ethoxy, $100 \mathrm{cp}$ grade) and liquid paraffin were purchased from Wako Pure Chemical Industies, Ltd. (Osaka, Japan). All other chemicals were of reagent grade.

Fluoroscein thiocarbamyl (FTC)-chitosan (FTC-chi) was synthesized as reported previously. ${ }^{14)}$ Briefly, Chi $(500 \mathrm{mg})$ was dissolved in $500 \mathrm{ml}$ of aqueous solution by adjusting $\mathrm{pH}$ to 3 with $1 \mathrm{~N}$ aqueous $\mathrm{HCl}$ solution, and then the solution $\mathrm{pH}$ was returned to 6.5 with $1 \mathrm{~N}$ aqueous $\mathrm{NaOH}$ solution. FITC $(15 \mathrm{mg})$ was dissolved in $30 \mathrm{ml}$ of water and added to the chitosan solution, and the mixture was stirred for $24 \mathrm{~h}$ at room temperature in the dark. Then, the solution $\mathrm{pH}$ was adjusted to 9 with $1 \mathrm{~N}$ aqueous $\mathrm{NaOH}$ solution, and the resultant precipitate was collected by centrifugation. The product was dissolved in $1 \mathrm{~N}$ aqueous $\mathrm{HCl}$ solution, precipitated by addition of $1 \mathrm{~N}$ aqueous $\mathrm{NaOH}$ solution and collected by centrifugation. The precipitate was washed with a mixture of acetone-water $(3: 1, \mathrm{v} / \mathrm{v})$ and dried in vacuo to yield FTC-chi. FTC content of FTC-chi was calculated to be $0.66 \%(\mathrm{w} / \mathrm{w})$ from the fluorometrical measurement.

Preparation of Microparticles 1) Cephradine-containing ethylcellulose microparticles (MPC): Ethylcellulose $(2.4 \mathrm{~g})$ was dissolved in $30 \mathrm{ml}$ of acetone, and cephradine $(1.2 \mathrm{~g})$ was suspended in this solution. The suspension was added drop-wise to $300 \mathrm{ml}$ of liquid paraffin containing SS30 at $0.2 \%(\mathrm{w} / \mathrm{v})$ with stirring at room temperature, heated gradually to $60^{\circ} \mathrm{C}$, and stirred for $6 \mathrm{~h}$ at $60^{\circ} \mathrm{C}$. Then, the microparticles thus produced were separated from the mixture by centrifugation, and washed thoroughly with $n$-hexane to give MPC. 2) chitosan-coated cephradine-containing ethylcellulose microparticles (Chi-MPC): MPC $(60 \mathrm{mg})$ were dispersed into $0.5 \mathrm{ml}$ of $2 \%(\mathrm{w} / \mathrm{v})$ chitosan solution in aqueous acetic acid. After fairly drying the mixture, it was sieved with 50-mesh. The obtained wet chitosan-coated MPC were 
washed using $8 \%(\mathrm{w} / \mathrm{v})$ aqueous ammonia solution and water in this order, and dried in air. Finally, Chi-MPC were obtained by passing through the 50-mesh. 3) FTC-chi-coated ethylcellulose microparticles without cephradine (FTC-chiMP): Ethylcellulose microparticles without cephradine, MP, were prepared in the same manner as MPC except that cephradine was not used. Preparation of FTC-chi-MP was performed in the same method as Chi-MPC except that MP was used instead of MPC and FTC-chi was used instead of chitosan. MPC and Chi-MPC were used in the in vitro release experiment and in vivo absorption study. FTC-chi-MP were used in the intestinal mucoadhesion experiment.

Particle Characteristics The particle size was examined by microscopic measurement of the Green diameters for 200 microparticles chosen at random. The amount of FTC-chi in FTC-chi-MP was measured as follows: A small amount of FTC-chi-MP was put in small volume of $2 \%(\mathrm{v} / \mathrm{v})$ acetic acid to dissolve the FTC-chi layer. The FTC-chi solution was separated from MP by centrifugation, and diluted using $0.1 \mathrm{M} \mathrm{ac}-$ etate buffer, $\mathrm{pH}$ 4.5. The FTC-chi amount was obtained by measuring the FTC-chi concentration of the diluted solution fluorometrically (Ex. $490 \mathrm{~nm}$; Em. $520 \mathrm{~nm}$ ).

Intestinal Transit after Intraduodenal Administration FTC-chi-MP were used in this experiment. Male Wistar rats $(240-270 \mathrm{~g})$ underwent fast for $24 \mathrm{~h}$, and then were anesthetized by intraperitoneal administration of urethane solution in saline at $0.9 \mathrm{~g} / 4 \mathrm{ml} / \mathrm{kg}$. The rats were placed on their backs on a warm plate set at $40{ }^{\circ} \mathrm{C}$ throughout the experiment. The abdominal skin and membrane were cut open, FTC-chi-MP $(50 \mathrm{mg})$, which were suspended in $1 \mathrm{ml}$ of saline, were administered into the intestine $3 \mathrm{~cm}$ distance from the pylorus using an oral sound. Then, the part below the rift for administration was ligatured to prevent leakage. The incisions of the abdominal membrane and skin were then sutured. At 2, 5 and $8 \mathrm{~h}$ after administration, the small intestine was excised, and the rat was sacrificed immediately by excessive anesthesia with ether. The small intestine thus obtained was divided into 6 parts of equal length $(12-15 \mathrm{~cm})$. Each part was turned inside out, and the microparticles were collected by scratching the mucosal surface with a spatula. The collected sample was homogenized using a glass homogenizer with a Teflon pestle, and $5 \mathrm{ml}$ of $0.1 \mathrm{M}$ acetate buffer, $\mathrm{pH} 4.5$, was added to dissolve the FTC-chi. After centrifugation, the supernatant was analyzed fluorometrically (Ex. $490 \mathrm{~nm}$; Em. $520 \mathrm{~nm}$ ) to determine the FTC-chi concentration. The distributed amount of FTC-chi-MP was calculated from the FTC-chi concentration. The recoveries of FTC-chiMP were high (more than $80 \%$, w/w). Therefore, the results were evaluated with no correction.

In Vitro Release The release characteristics of cephradine from MPC and Chi-MPC were examined in vitro. They were dispersed into $500 \mathrm{ml}$ of the JP 14 second fluid, $\mathrm{pH} 6.8$, which was stirred using a paddle at $50 \mathrm{rpm}$ at $37^{\circ} \mathrm{C}$. Aliquots $(5 \mathrm{ml})$ were taken at appropriate time points, and immediately after each sampling $5 \mathrm{ml}$ of the fresh JP 14 second fluid, pH 6.8, was added to the tested medium. Each sample was filtered using a membrane filter $(0.45 \mu \mathrm{m}$ pore diameter $)$. The filtrate was measured spectrophotometrically at $254 \mathrm{~nm}$.

In Vivo Absorption Study Male Wistar rats (240$270 \mathrm{~g}$ ) underwent fast for $24 \mathrm{~h}$, and then were anesthetized by intraperitoneal administration of urethane solution in saline at $0.9 \mathrm{~g} / 4 \mathrm{ml} / \mathrm{kg}$. The rats were placed on their backs on a warm plate set at $40{ }^{\circ} \mathrm{C}$ throughout the experiment. 1) Intravenous administration of cephradine solution and intraduodenal administration of cephradine solution and suspension: Cephradine solution in saline was administered at the dose of $5 \mathrm{mg}$ cephradine $/ \mathrm{ml} / \mathrm{kg}$ from the jugular vein for intravenous administration. Cephradine solution in saline $(1 \mathrm{ml})$ and cephradine suspension in saline $(1 \mathrm{ml})$ were administered intraduodenally at doses of $40 \mathrm{mg}$ cephradine $/ \mathrm{kg}$ and $100 \mathrm{mg}$ cephradine $/ \mathrm{kg}$, respectively. The intraduodenal administration was performed in the same manner as described above in intestinal transit after intraduodenal administration except that the operation for excision of the small intestine was not performed. At appropriate time points, blood samples $(200 \mu \mathrm{l})$ were withdrawn from the jugular vein using a heparinized syringe, and centrifuged at $3000 \mathrm{rpm}$ for $20 \mathrm{~min}$ to obtain the plasma. Water $(50 \mu \mathrm{l})$ and acetonitrile $(500 \mu \mathrm{l})$ were added to $50 \mu \mathrm{l}$ of the plasma, mixed vigorously for $1 \mathrm{~min}$, and centrifuged at $3000 \mathrm{rpm}$ for $10 \mathrm{~min}$. Five hundred microliters of the supernatant was taken, and the solvent was evaporated at $35^{\circ} \mathrm{C}$ under nitrogen gas. The resultant residue was dissolved in $200 \mu \mathrm{l}$ of $5 \mathrm{~mm}$ ammonium acetate aqueous solution containing acetonitrile at $10 \%(\mathrm{v} / \mathrm{v})$. After filtration of the solution with a membrane filter $(0.45 \mu \mathrm{m}$ pore diameter), the filtrate was analyzed by high-performance liquid chromatography (HPLC). 2) Intraduodenal administration of MPC and Chi-MPC: MPC and Chi-MPC $(1 \mathrm{ml})$ were administered at a dose of $100 \mathrm{mg}$ cephradine $/ \mathrm{kg}$. The intraduodenal administration, blood sampling and treatment of the samples were performed in the same manner as described for cephradine solution or suspension. The final filtrated samples were analyzed by HPLC.

HPLC Assay HPLC assay was performed at room temperature. Twenty microliters of the sample was injected into a Nucleosil $100-5 \mathrm{C}_{18}$ analytical column $(4.6 \mathrm{~mm}$ in inner diameter $\times 150 \mathrm{~mm}$ in length) connected to an RP-18 NEWGUARD 7 micron guard column (3.2 in inner diameter $\times$ $15 \mathrm{~mm}$ in length), which was attached to a Shimadzu LC6AD apparatus with a Shimadzu SPD-10AV UV detector adjusted at $254 \mathrm{~nm}$. Ammonium acetate aqueous solution $(5 \mathrm{~mm})$ containing acetonitrile at $10 \%(\mathrm{v} / \mathrm{v})$ was used as a mobile phase at a flow rate of $1.0 \mathrm{ml} / \mathrm{min}$. The concentration of cephradine was determined using the absolute calibration curve method.

Pharmacokinetic Analysis The pharmacokinetic characteristics were analyzed by calculating $C_{\max }, T_{\max }, A U C$, $M R T$ and $V R T$. The $A U C, M R T$ and $V R T$ values were calculated as follows:

$$
\begin{aligned}
& A U C=\int_{0}^{\infty} C_{\mathrm{p}} d t \\
& M R T=\int_{0}^{\infty}\left(C_{\mathrm{p}} \times t\right) d t / A U C \\
& V R T=\int_{0}^{\infty}\left\{C_{\mathrm{p}} \times(t-M R T)^{2}\right\} d t / A U C
\end{aligned}
$$

In each equation, $C_{\mathrm{p}}$ represents the plasma concentration at time $t$. The calculation was performed by the trapezoidal method within the range where the plasma concentrations were determined. The calculation for the infinite time was 
based on the extrapolation by presuming that the plasma level in the latter phase should decline following the monoexponential curve.

\section{RESULTS}

Particle Characteristics MP and MPC showed a mean particle diameter of $50 \mu \mathrm{m}$. The mean particle diameter of FTC-chi-MP and Chi-MPC was $75 \mu \mathrm{m}$. The content of FTCchi in FTC-chi-MP was $11 \%(\mathrm{w} / \mathrm{w})$. The cephradine content in MPC was $20 \%(\mathrm{w} / \mathrm{w})$, and that drug content was retained well in Chi-MPC.

Intestinal Transit Characteristics after Intraduodenal Administration FTC-chi-MP were used in this experiment, and their transit was calculated based on the distribution of FTC-chi. They were distributed mainly in the upper part of the small intestine, duodenal and jejunum at 2 and $5 \mathrm{~h}$ post-administration (Fig. 1). Even at $8 \mathrm{~h}$ after administration, most of them was distributed from the upper to middle parts, and only less than $10 \%$ was observed at the lower part (Fig. 1). Phenol red-containing ethylcellulose microparticles were similarly prepared, administered in the similar manner, and investigated with regard to the intestinal movement of phenol red by referring to the reports by Sawamoto et al. and Sugimoto et al. ${ }^{13,22)}$ The phenol red was distributed mainly in the middle parts of the small intestine at $5 \mathrm{~h}$ post-administration, and it transferred mainly to the lower part of the small intestine at $8 \mathrm{~h}$ post-administration (data not shown).

In Vitro Release Cephradine was decomposed slowly in the JP 14 second fluid, $\mathrm{pH} 6.8$, at $37^{\circ} \mathrm{C}$. The UV absorption at $254 \mathrm{~nm}$ was reduced by nearly $1 \%$ through $1 \mathrm{~h}$ storage under these conditions. Therefore, the release profiles were described for the tests in $0-4 \mathrm{~h}$. The percentage released was not corrected for the above loss of UV absorption. MPC and Chi-MPC showed very similar release profiles (Fig. 2). Cephradine was released gradually from both preparations.

In Vivo Absorption 1) Intravenous and Intraduodenal Administration of Cephradine Solution and Intraduodenal Administration of Cephradine Suspension: Cephradine was eliminated quickly from the systemic circulation after intravenous injection, and was not detected after $8 \mathrm{~h}$ post-injection (Fig. 3). After intraduodenal administration, the cephradine suspension $(100 \mathrm{mg}$ cephradine/ml) showed approximately double the plasma level of the cephradine solution (40 mg cephradine $/ \mathrm{kg}$ ). The cephradine suspension and solution showed similar plasma concentration-time patterns and the maximum plasma levels at $1 \mathrm{~h}$ post-administration (Fig. 3). After $1 \mathrm{~h}$ post-administration, the plasma concentrations decreased sharply. The cephradine solution gave a concentration of less than $1 \mu \mathrm{g} / \mathrm{ml}$ after $12 \mathrm{~h}$ post-administration. The cephradine suspension showed concentrations of nearly $5 \mu \mathrm{g} / \mathrm{ml}$ at $12 \mathrm{~h}$ post-administration and of less than $1 \mu \mathrm{g} / \mathrm{ml}$ at $24 \mathrm{~h}$ post-administration.

2) Intraduodenal Administration of MPC and Chi-MPC: MPC and Chi-MPC showed similar maximum concentrations of approximately $12 \mu \mathrm{g} / \mathrm{ml}$ at $2 \mathrm{~h}$ after intraduodenal administration at a dose of $100 \mathrm{mg}$ cephradine $/ \mathrm{kg}$ (Fig. 4). In the case of MPC, the plasma concentration was decreased to a quarter of the maximum level at $5 \mathrm{~h}$ post-inoculation, and to approximately $1 \mu \mathrm{g} / \mathrm{ml}$ at $12 \mathrm{~h}$ post-inoculation. On the other hand, Chi-MPC showed good maintenance of the plasma

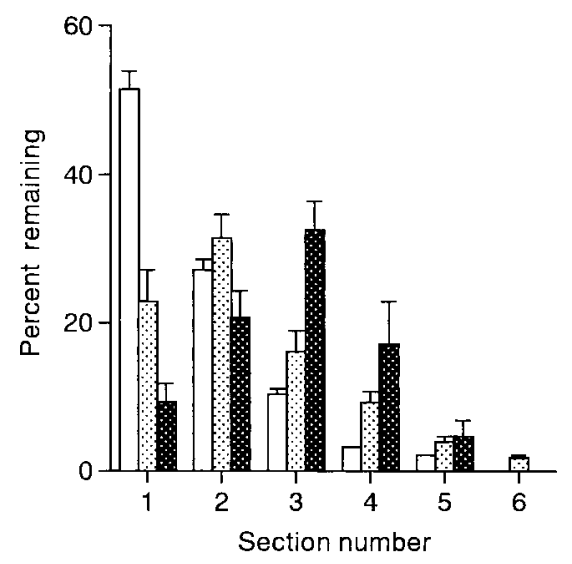

Fig. 1. Intestinal Transit of FTC-chi-MP after Intraduodenal Administration

$\square 2 \mathrm{~h}$ post-administration; $5 \mathrm{~h}$ post-administration; Each column represents the mean \pm S.D. $(n=3)$.

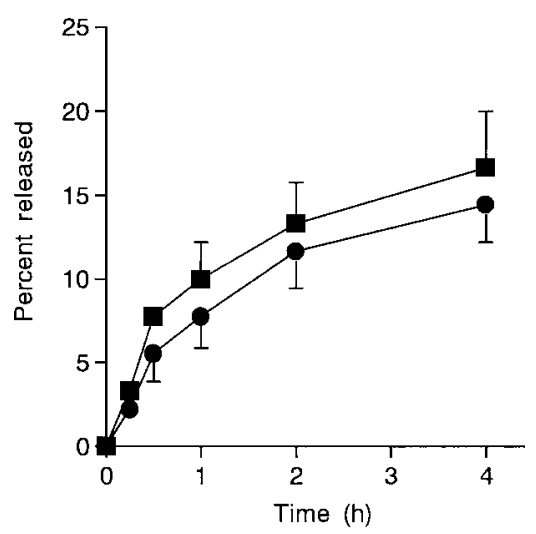

Fig. 2. Release of Cephradine from MPC ( $\mathbf{\square})$ and Chi-MPC (@) in JP 14 Second Fluid, $\mathrm{pH} 6.8$, at $37^{\circ} \mathrm{C}$

Each point represents the mean \pm S.D. $(n=3)$.

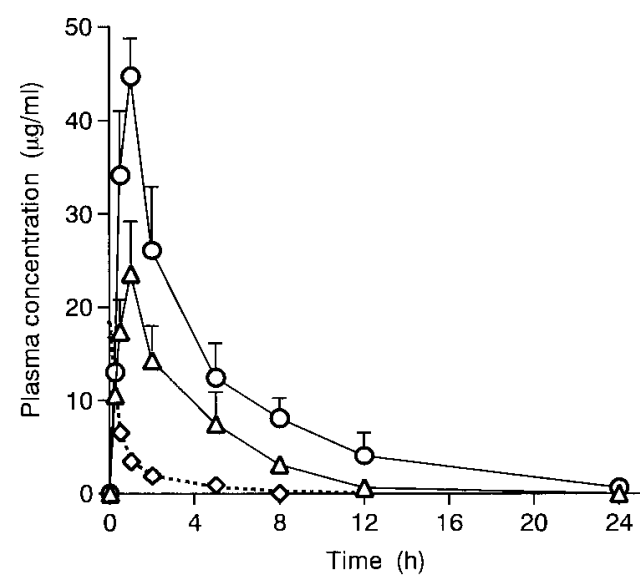

Fig. 3. Plasma Concentration-Time Profiles of Cephradine after Intravenous and Intraduodenal Administration in Rats

$\diamond$ intravenous administration of cephradine solution ( $5 \mathrm{mg}$ cephradine $/ \mathrm{kg}$ ); $\triangle$ intraduodenal administration of cephradine solution ( $40 \mathrm{mg}$ cephradine $/ \mathrm{kg}$ ); $\bigcirc$ intraduodenal administration of cephradine suspension ( $100 \mathrm{mg}$ cephradine $/ \mathrm{kg}$ ). Each point represents the mean \pm S.D. ( $n=3$ intravenous administration; $n=4-5$ intraduodenal administration). The broken line shows the plasma concentration-time profile calculated for intravenous administration by equation 4 . 
concentration. That is, Chi-MPC exhibited plasma concentrations of $5 \mu \mathrm{g} / \mathrm{ml}$ at $12 \mathrm{~h}$ post-inoculation and of more than $2 \mu \mathrm{g} / \mathrm{ml}$ at 24 post-administration.

Pharmacokinetic Characteristics The mean plasma concentration-time profile after intravenous injection of cephradine solution was fitted to the two-compartment model. As a result, it was expressed as the following equation:

$$
C_{\mathrm{iv}}(t)=14.7 \exp (-2.91 t)+3.64 \exp (-0.335 t)
$$

where $C_{\text {iv }}(t)$ meant the plasma concentration $(\mu \mathrm{g} / \mathrm{ml})$ at time $t(\mathrm{~h})$. When the $A U C\left(0-{ }^{\circ}\right)$ at this intravenous injection, $A U C$ (iv), was calculated using equation 4 , it was 15.9 $\mu \mathrm{g} \cdot \mathrm{h} / \mathrm{ml}$. The dosage forms administered intraduodenally were analyzed comparatively for pharmacokinetic parameters, and their absolute bioavailability was calculated from $($ Dose $(\mathrm{iv}) \times A U C(\mathrm{id})) /($ Dose $(\mathrm{id}) \times A U C(\mathrm{iv}))$, where Dose(iv) and $A U C(\mathrm{iv})$ were $5(\mathrm{mg} / \mathrm{kg})$ and $15.9(\mu \mathrm{g} \cdot \mathrm{h} / \mathrm{ml})$, respectively, and $D o s e($ id) and $A U C($ id) were the dose and $A U C(0-$ $\left.{ }^{\circ}\right)$ value at the intraduodenal administration, respectively (Table 1). Solution and suspension of cephradine showed higher $C_{\max }$ values. Cephradine solution $(40 \mathrm{mg}$ cephradine/ $\mathrm{kg}$ ) showed bioavalability of more than $80 \%$. The cephradine suspension (100 mg cephradine $/ \mathrm{kg}$ ) showed approximately double the $A U C$ of the cephradine solution ( $40 \mathrm{mg}$ cephradine $/ \mathrm{kg}$ ). The $A U C$ of Chi-MPC was slightly lower than that of the cephradine suspension at a dose of $100 \mathrm{mg}$ cephra-

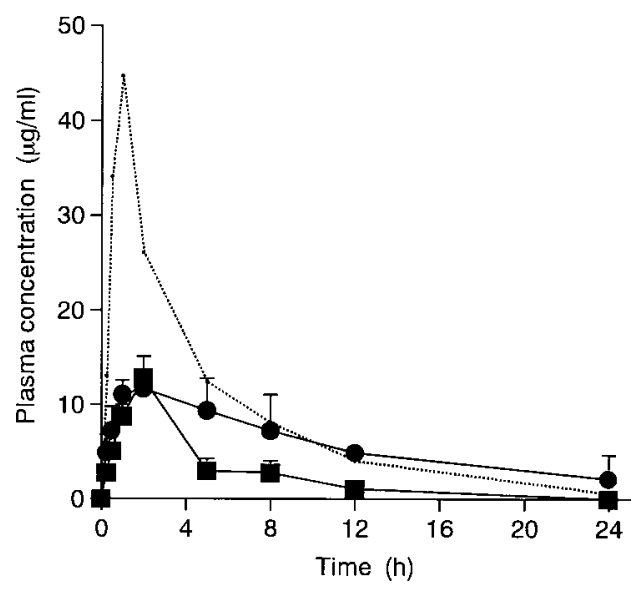

Fig. 4. Plasma Concentration-Time Profiles of Cephradine after Intraduodenal Administration in Rats

- intraduodenal administration of MPC (100 mg cephradine $/ \mathrm{kg})$; 0 intraduodenal administration of Chi-MPC (100 mg cephradine/kg). Each point represents the mean \pm S.D. $(n=4-5)$. The dotted line indicates the mean plasma concentrationtime profile for cephradine suspension administered intraduodenally $(100 \mathrm{mg}$ cephradine $/ \mathrm{kg}$ ), which is described in Fig. 3. dine/kg. MPC exhibited much lower $A U C$ than the cephradine suspension and Chi-MPC at a dose of $100 \mathrm{mg}$ cephradine $/ \mathrm{kg}$. The bioavailability of Chi-MPC was calculated as approximately $50 \%$. The bioavailabilities were in the order of suspension $>$ Chi-MPC $\gg$ MPC. Chi-MPC showed nearly three times larger $M R T$ value than the cephradine solution and MPC, and more than twice larger MRT value than the cephradine suspension.

\section{DISCUSSION}

Ethylcellulose microcapsules are often used to make prolonged release dosage forms. ${ }^{1,7,8}$ Such prolonged release dosage forms are often utilized to avoid frequent dosing of drugs that show a short biological half life. ${ }^{6}$ These systems are available for drugs the plasma concentration of which is critically related to efficacy. That is, such systems can achieve maintenance of drug concentration at the therapeutic range in the body. The concentration of a drug unbound with plasma protein is directly related to its efficacy. In the present study, the antibiotic agent cephradine, ${ }^{15-21)}$ which shows a short biological half life, was chosen as a model drug, and a prolonged release dosage form was developed.

Although prolonged release dosage forms orally administered are often useful for sustained action of drugs, they may not be available for maintenance of drug effects when the limited absorption window exists in the gastrointestinal tract. ${ }^{12)}$ When the absorption area is limited, the drug has to be localized at the absorption window to maintain the effect. In order to achieve good drug absorption in such case, two functions are required to the dosage form. That is, abilities to reside at an absorption window and to exhibit prolonged drug release are needed. Mucoadhesive polymers are available for localization or slow transit of microparticles at the gastrointestinal tract. ${ }^{7,9-14)}$ In this study, ethylcellulose was used to prepare microparticles showing prolonged release of cephradine, and chitosan was applied to give the microparticles mucoadhesive characteristics.

All the microparticles prepared were sufficiently small to move through the intestinal tract. FTC-chi-MP showed good retention in the small intestine (Fig. 1). This effect was considered due to mucoadhesive properties of chitosan. Similar phenomena were previously found. ${ }^{7,14)}$ The drug movements in solution and microparticulate oral dosage forms had been examined by Sugimoto et al. and Sawamoto et al., who used phenol red as a transit marker in the examination of the gastrointestinal transit. ${ }^{13,22)}$ The present experimental conditions were different from those by Sugimoto et al. and Sawamoto

Table 1. Pharmacokinetic Parameters for Each Dosage Form Administered Intraduodenally in Rats

\begin{tabular}{|c|c|c|c|c|c|c|c|}
\hline Dosage form & $\begin{array}{c}\text { Dose } \\
\text { (mg cephradine/kg) }\end{array}$ & $\begin{array}{c}C_{\max }^{a)} \\
(\mu \mathrm{g} / \mathrm{ml})\end{array}$ & $\begin{array}{l}T_{\max }^{a)} \\
\text { (h) }\end{array}$ & $\begin{array}{c}A U C\left(0-{ }^{\circ}\right)^{a, b)} \\
\quad(\mu \mathrm{g} \cdot \mathrm{h} / \mathrm{ml})\end{array}$ & $\begin{array}{c}\operatorname{MRT}\left(0 \mathrm{C}^{\circ}\right)^{a, b)} \\
\text { (h) }\end{array}$ & $\begin{array}{c}\operatorname{VRT}\left(0 \mathrm{C}^{2}{ }^{\circ}\right. \\
)^{a, b)}\end{array}$ & $\begin{array}{l}\text { B.A. }{ }^{c)} \\
(\%)\end{array}$ \\
\hline Solution & 40 & $23.9 \pm 5.3$ & $1.0 \pm 0.0$ & $102.4 \pm 11.3$ & $4.1 \pm 0.5$ & $18.1 \pm 5.7$ & 80.3 \\
\hline Suspension & 100 & $44.5 \pm 4.1$ & $1.0 \pm 0.0$ & $207.2 \pm 29.5$ & $5.6 \pm 1.5$ & $36.0 \pm 18.3$ & 65.0 \\
\hline MPC & 100 & $12.6 \pm 2.4$ & $2.0 \pm 0.0$ & $55.0 \pm 9.8$ & $4.5 \pm 1.3$ & $22.1 \pm 13.0$ & 17.2 \\
\hline Chi-MPC & 100 & $11.8 \pm 0.4$ & $1.8 \pm 0.4$ & $161.1 \pm 55.1$ & $12.7 \pm 2.6$ & $173.2 \pm 82.0$ & 50.5 \\
\hline
\end{tabular}

a) Each value represents the mean \pm S.D. $(n=4-5)$. b) $\left(0-{ }^{\circ}\right)$ means calculation from 0 to infinit time. $\left.\quad c\right)$ B.A. means the absolute bioavailability for each dosage form, and was calculated by the following equation: B.A. $(\%)=100 \times($ Dose $(\mathrm{iv}) \times A U C(\mathrm{id})) /(\operatorname{Dose}(\mathrm{id}) \times A U C(\mathrm{iv}))$, where Dose (iv) and $A U C(\mathrm{iv}) \mathrm{were} 5(\mathrm{mg} / \mathrm{kg})$ and $15.9(\mu \mathrm{g} \cdot \mathrm{h} / \mathrm{ml})$, respectively, and Dose(id) and $A U C$ (id) were the dose and mean $A U C$ value, respectively, for the intraduodenally administered dosage form shown in this table. The details are described in the text. 
et al. ${ }^{13,22)}$ in particle size, anesthetization condition and administration site, but the results were basically consistent. Namely, non-coated ethylcellulose MPC moved fairly fast in the intestine, but the movement of the ethylcellulose MPC was slowered by coating with the bioadhesive polmer, chitosan. Further, Chi-MPC showed a gradual drug release similar to that of MPC (Fig. 2). The chitosan coating layer did not influence the release rate, indicating that this layer should be high permeable to cephradine. These characteristics demonstrated that Chi-MPC fulfilled both prolonged intestinal residence and slow drug release.

After intravenous administration, cephradine was eliminated rapidly from the blood circulation (Fig. 3), and the mean plasma concentration-time profile was analyzed by the two-compartment model. The $A U C$ calculated for intravenous injection was used for calculation of absolute bioavalability for each doasge form. Cephradine was considered to be well absorbed in the solution dosage form, which showed the bioavailability of more than $80 \%$. In the cephradine suspension, its considerable part was dissolved but some remained as powder solid. The dissolution of the solid part may take some time, resulting in less bioavailability or prolonged absorption.

After intraduodenal administration of MPC and Chi-MPC, both suppressed $C_{\max }$ and prolonged $T_{\max }$, which meant prolonged release of cephradine (Table 1). At $5 \mathrm{~h}$ post-administration, the plasma concentration for MPC was reduced to $3 \mu \mathrm{g} / \mathrm{ml}$, which was a quarter of the $C_{\max }$ value. On the other hand, Chi-MPC maintained a higher plasma level of cephradine (Fig. 4). At $12 \mathrm{~h}$ post-administration, Chi-MPC showed a higher plasma concentration than the cephradine suspension. MPC were considered to move to non- or less-absorbable parts faster than Chi-MPC because MPC did not include a mucoadhesive polymer. As far as we know, cephradine is absorbed in the small intestine, but the feature about its absorption window is not shown clearly. ${ }^{23-27)}$ Cephalexin, a structually similar $\beta$-lactam antibiotic, is reportedly absorbed highly in duodenum and jejunum, ${ }^{22}$ indicating that absorbtion abilitity appeared to be varied in the sites of the small intestine. The present result suggested that the localization of cephradine in the upper and middle parts of the small intestine might be advantageous for high absorption. The $A U C$ of Chi-MPC was slightly less than that of the cephradine suspension, and the bioavailability of Chi-MPC was approximately $50 \%$ (Table 1 ), which might be related to the slow drug release. The in vitro release profile (Fig. 2) suggested that one day might be needed for the release of half of the dose, but this might not be consistent completely with the in vivo absorption. It is not always easy to estimate the bioavailability exactly from the in vitro release because the situations are different between the in vitro and in vivo releases. For example, Tuncel et al. reported that the release was faster in vivo than in vitro in cephradine microcapsules and tablets. ${ }^{18)}$ For the present results, the consistency between in vitro release and in vivo absorption appeared not to be complete but fairly good. The in vivo release and absorption features in the small intestine will have to be investigated in more detail to discuss relationship of them exactly. For antibiotics such as cephradine, maintenance of plasma concentration is essential for therapeutic efficacy; that is, plasma concentration must be maintained above minimum inhibitory concentration (MIC) to maintain the therapeutic effect. ${ }^{15,28)}$ MIC values vary depending on the species of bacteria and antibiotic compound. The MIC values of cephradine were reported to range from a few to several dozen $\mu \mathrm{g} / \mathrm{ml}$ for many bacteria. ${ }^{19-21)}$ The concentration of drug unbound with plasma protein is directly related to MIC. ${ }^{15,23)}$ As the protein binding of cephradine is low, ${ }^{15)}$ Chi-MPC are considered to maintain the effective concentration for a long time. Thus, chitosan-coated ethylcellulose microparticles were suggested to be possibly useful to achieve a prolonged maintenance of effective concentration of drugs with a short biological half life and limited absorption area.

Acknowledgments The authors are very grateful to Ms. Reiko Yahagi for technical assistance in the experiments.

\section{REFERENCES}

1) Uchida T., Fujimoto I., Goto S., Aoyama T., Yakuzaigaku, 47, 254259 (1987).

2) Harland R. S., Gazzaniga A., Sangalli M. E., Colombo P., Peppas N. A., Pharm. Res., 5, 488-494 (1988).

3) Chitnis V. S., Malshe V. S., Lalla J. K., Drug Dev. Ind. Pharm., 17, 879-892 (1991).

4) Ozdemir N., Ordu S., Ozkan Y., Drug Dev. Ind. Pharm., 26, 857-866 (2000).

5) Wei Z., Yu Z., Bi D., Drug Dev. Ind. Pharm., 27, 469-474 (2001).

6) El Khodairy K. A., Eshra A. G., Nada A. H., Mortada S. A., J. Microencapsulation, 9, 365-373 (1992).

7) Yamada T., Onishi H., Machida Y., Yakugaku Zasshi, 121, 239-245 (2001).

8) Yamada T., Onishi H., Machida Y., J. Control. Release, 75, 271-282 (2001).

9) Lehr C.-M., Bouwstra J. A., Kok W., De Boer A. G., Tukker J. J., Verhoef J. C., Breimer D. D., Junginger H. E., J. Pharm. Pharmacol., 44, 402-407 (1992).

10) Takeuchi H., Yamamoto H., Niwa T., Hino T., Kawashima Y., Pharm. Res., 13, 896-901 (1996).

11) Kawashima Y., Yamamoto H., Takeuchi H., Kuno Y., Pharm. Dev. Technol., 5, 77-85 (2000).

12) Longer M. A., Ching H. S., Robinson J. R., J. Pharm. Sci., 74, 406411 (1985).

13) Sugimoto K., Yoshida M., Yata T., Higaki K., Kimura T., Biol. Pharm. Bull., 21, 1202-1206 (1998).

14) Shimoda J., Onishi H., Machida Y., Drug Dev. Ind. Pharm., 27, 567576 (2001).

15) Singhvi S. M., Heald A. F., Schreiber E. C., Chemotherapy, 24, 121133 (1978).

16) Uchida T., Goto S., Chem. Pharm. Bull., 36, 2135-2144 (1988).

17) Nakashima E., Matsushita R., Takeda M., Nakanishi T., Ichimura F., Drug Metab. Dispos., 20, 730-735 (1992).

18) Tuncel T., Bergisadi N., Akin L., Otuk G., Kuscu I., Pharmazie, 51, 168-171 (1996).

19) Jones R. N., Thornsberry C., Barry A. L., Fuchs P. C., Gavan T. L., Gerlach E. H., J. Antibiot., 30, 583-592 (1977).

20) Shadomy S., Wagner G., Carver M., Antimicrob. Agents Chemother., 12, 609-613 (1977).

21) Drabu Y. J., Mehtar S., Blakemore P. H., Drugs Exptl. Clin. Res., 13, 201-203 (1987).

22) Sawamoto T., Haruta S., Kurosaki Y., Higaki K., Kimura T., J. Pharm. Pharmacol., 49, 450_457 (1997).

23) Miyazaki K., Ohtani K., Umeniwa K., Arita T., J. Pharmacobio-Dyn., 5, 555-563 (1982).

24) Nakashima E., Tsuji A., Kagatani S., Yamana T., J. PharmacobioDyn., 7, 452-464 (1984).

25) Tsuji A., Tamai I., Nakanishi M., Terasaki T., Hamano S., J. Pharm. Pharmacol., 45, 996-998 (1993).

26) Yuasa H., Amidon G. L., Fleisher D., Pharm. Res., 10, 400-404 (1993).

27) Terada T., Saito H., Mukai M., Inui K., Am. J. Physiol., 273, F706F711 (1997).

28) Hoffman A., Danenberg H. D., Katzhendler I., Shuval R., Gilhar D., Friedman M., J. Control. Release, 54, 29-37 (1998). 